\title{
La tomografía computada durante la niñez y la adolescencia se asocia a mayor riesgo de cáncer
}

\author{
Computed tomography in childhood and adolescence is associated with increased cancer risk
}

\section{Objetivo}

Establecer la relación entre la exposición a la tomografía computada (TC) y el desarrollo de cáncer en niños y adolescentes.

\section{Diseño, lugar y población}

Estudio de cohorte que incluyó 10,9 millones de personas identificadas a partir de los registros del sistema de seguro médico de Australia (Australian Medicare) de 0 a 19 años de edad. Se identificaron todas las exposiciones a TC desde 1985 a 2005. Los cánceres diagnosticados fueron obtenidos a través de los registros nacionales de cáncer.

\section{Medición de resultados principales}

Tasas de incidencia de cáncer en individuos expuestos a TC,
Mathews JD y col. BMJ 2013;346:\{2360

al menos un año antes del diagnóstico de cualquier cáncer, en comparación con individuos no expuestos.

\section{Resultados principales}

Se registraron 60.674 cánceres en 680.211 personas expuestas a TC. La duración media del seguimiento después de la exposición fue de 9,5 años.

La incidencia de cáncer fue $24 \%$ mayor en las personas expuestas a TC, siendo el riesgo relativo (RR) 1,24 (IC 95\% 1,20 a 1,29), $p<0,001$.E I RR se incrementó 0,16 (IC 95\% 0,13 a 0,19 ) por cada TC adicional y fue mayor cuando la exposición fue a edades más jóvenes ( $p<0,001)$.

Tabla 1: Resultados por edad de la primera exposición

\begin{tabular}{c|c|c|c|c|}
\hline \multirow{2}{*}{ Total de canceres } & \multicolumn{4}{|c|}{ Edad (años) } \\
\cline { 2 - 5 } & $\mathbf{0}$ a 4 & $\mathbf{5}$ a 9 & $\mathbf{1 0}$ a 14 & $\mathbf{1 5}$ a 19 \\
\hline $\mathbf{R R}(\mathbf{I C}$ 95\%) & $1,72(1,44$ a 2,05$)$ & $1,40(1,25$ a 1,58$)$ & $1,21(1,13$ a 1,30$)$ & $1,21(1,16$ a 1,27$)$ \\
\hline
\end{tabular}

\section{Conclusiones}

El aumento la de incidencia de cáncer después de la exposición a TC en esta cohorte podría deberse a radiación. Debido a que este aumento persistía al final del seguimiento, no fue posible determinar el riesgo de por vida de la exposición a TC en estos pacientes.

Fuente de financiamiento: No referidos.

\section{Comentario}

Aunque se sabe con certeza que grandes dosis de radiación ionizante causan cáncer, existe incertidumbre sobre los riesgos de la TC como fuente de baja dosis. Un estudio reciente de 180.000 jóvenes expuestos a TC en Reino Unido encontró un mayor riesgo de leucemia y cáncer de cerebro con el aumento de la dosis de radiación' ${ }^{1}$. El presente estudio demostró que en 680.000 australianos de 0 a 9 años expuestos a TC, la incidencia de cáncer se incrementó en un $24 \%$. El aumento proporcional del riesgo en el grupo expuesto fue mayor a edades más tempranas.

El riesgo de la utilización de TC en pacientes pediátricos puede reducirse evitando indicaciones innecesarias y garantizando su realización con una técnica óptima ${ }^{2}$. Afortunadamente muchos radiólogos son conscientes de los riesgos, y los avances tecnológicos han permitido reducir las dosis de TC manteniendo la calidad diagnóstica ${ }^{3}$. Sin embargo, las herramientas de decisión para evaluar la necesidad de una TC aún no se uti- lizan de forma rutinaria ${ }^{4}$. El trauma encefalocraneano sigue representando la mayor parte de las indicaciones de TC en niños ${ }^{5}$.

\section{Conclusiones del comentador}

Si bien la TC es de gran utilidad para el diagnóstico y el seguimiento de numerosas patologías en niños y adolescentes, no es inocua, por lo que debería utilizarse de manera racional. Por tal motivo es indispensable que los médicos solicitantes justifiquen cada TC con indicaciones clínicas definidas, y que cada exploración sea optimizada para obtener imágenes diagnósticas con la menor exposición a radiación posible. El médico radiólogo cumple un rol importante en estos aspectos y debe ser consultadop or pacientes, familiares y médicos solicitantes ante cualquier duda.

\section{Marcos Quadrelli [ Serviciode Diagnóstico por Imágenes del Hospital Italiano de Buenos Aires. marcos.quadrelli@hospitalitaliano.org.ar]}

Quadrelli M. La tomografía computada durante la niñez y la adolescencia se asocia a mayor riesgo de cáncer. Evid Act Pract Ambul. 2014:17(3).JulSep. 87. Comentado de: Mathews JD y col. Cancer risk in 680,000 people exposed to computed tomography scans in childhood or adolescence: data linkage study of 11 million Australians. BMJ. 2013;346:f2360. PMID: 23694687.

\section{Referencia}

1.Pearce MS, et al. Radiation exposure from CT scans in childhood and subsequent risk of leukaemia and brain tumours: a retrospective cohort study. Lancet. 2012;380(9840):499-505. Epub 2012/06/12.

2. Brady Z, Cain TM, Johnston PN. Justifying referrals for paediatric CT. The Medical journal of Australia. 2012;197(2):95-9. Epub 2012/07/17.

3. Kim KP, et al. Development of a database of organ doses for paediatric and young adult CT scans in the United Kingdom. Radiation protection dosimetry. 2012;150(4):41526. Epub 2012/01/10

4. Gerdung C, Dowling S, Lang E. Review of the CATCH study: a clinical decision rule for the use of computed tomography in children with minor head injury. Cjem. 2012;14(4):243-7. Epub 2012/07/21.

5. Nigrovic LE, et al. The effect of observation on cranial computed tomography utilization for children after blunt head trauma. Pediatrics. 2011;127(6):1067-73. Epub 2011/05/11. 